\section{(A) Check for updates}

Cite this: Org. Chem. Front., 2019, 6 , 1796

Received 28th March 2019,

Accepted 17th April 2019

DOI: 10.1039/c9qo00447e

rsc.li/frontiers-organic

\title{
Radical addition of ketones and cyanide to olefins via acid catalyzed formation of intermediate alkenyl peroxides $\dagger$
}

\author{
Wen Shao, $\ddagger^{\mathrm{a}}$ Marcel Lux, ${ }^{\mathrm{a}}$ Martin Breugst (iD ${ }^{\mathrm{b}}$ and Martin Klussmann (iD *a $^{\mathrm{a}}$
}

A Brønsted acid catalyzed method was developed for the synthesis of $\gamma$-cyanoketones from sulfonyl cyanides, olefins and ketones. The reaction is believed to proceed via intermediate formation of alkenyl peroxides by condensation of ketones with tert-butylhydroperoxide. These unstable compounds decompose by homolytic $\mathrm{O}-\mathrm{O}$ bond cleavage, generating ketone-derived radicals which add to the olefins and generate the final products after reaction with the sulfonyl cyanide, thereby forming two new $\mathrm{C}-\mathrm{C}$ bonds. A range of different ketones and olefins can be used, including steroidal ketones and simple alkyl olefins. The products can be further transformed to substituted lactones and piperidines, including a tetracyclic one. This reaction can thus be utilized to gain access to complex molecules from simple starting materials in only a few synthetic steps.

\section{Introduction}

Radical addition reactions enable the double functionalization of olefins with heteroatom- and carbon-residues, thus much effort is put into their development. ${ }^{1}$ We have recently developed a method for the acid-catalyzed generation of radicals from ketones and hydroperoxides via the intermediate formation of alkenyl peroxides 1 (Scheme 1a). ${ }^{2}$ Alkenyl peroxides are highly unstable and can generally not be isolated at ambient temperature. ${ }^{3}$ Using this strategy, simple ketones can be utilized in radical reactions, for example towards the synthesis of $\gamma$-peroxyketones $2^{2 a}$ and heterocycles. ${ }^{4}$

The generation of radicals in the $\alpha$-position of ketones can be achieved by alternative means, ${ }^{5}$ but often it is only effective with 1,3-dicarbonyl compounds, ${ }^{6}$ at temperatures above $100{ }^{\circ} \mathrm{C},{ }^{7}$ with $\alpha$-bromo-ketones as substrates $^{8}$ and larger amounts of metal reagents, ${ }^{9}$ respectively. Their formation via alkenyl peroxides (1) by condensation with hydroperoxides, on the other hand, is particularly effective with plain ketones and only requires simple acids as catalysts. We were thus interested to extend the radical addition of ketones via this mechanism

\footnotetext{
${ }^{a}$ Max Planck Institut für Kohlenforschung, Kaiser-Wilhelm-Platz 2, 45470 Mülheim an der Ruhr, Germany.E-mail: klussmann@mpi-muelheim.mpg.de

${ }^{b}$ Universität zu Köln, Department für Chemie, Greinstraße 4, 50939 Köln, Germany $\dagger$ Electronic supplementary information (ESI) available: Detailed experimental and computational results. CCDC 1878410 . For ESI and crystallographic data in CIF or other electronic format see DOI: 10.1039/c9qo00447e

$\$$ Present address: Department of Organic Chemistry, University of Geneva, Quai Ernest Ansermet 30, 1211 Geneva 4, Switzerland.
}

to the twofold addition of carbon-radicals instead of the carboperoxidation as in the synthesis of 2 . Here, we report our results of the addition of ketones and cyanide to olefins (Scheme 1b).

We tested a variety of additional reagents to introduce a carbon residue instead of the peroxide group, but the peroxyketones 2 were always formed as major products. Overriding this preference was finally possible by employing sulfonyl cyanides 3 which led to formation of cyanoketones 4 . Sulfonyl cyanides are well-known reagents for the transfer of a cyano group to carbon-radicals. ${ }^{10}$ For example, the Landais group used para-toluenesulfonic cyanide $(p \mathrm{TsCN}, 3 \mathbf{3 a})$ in the radical

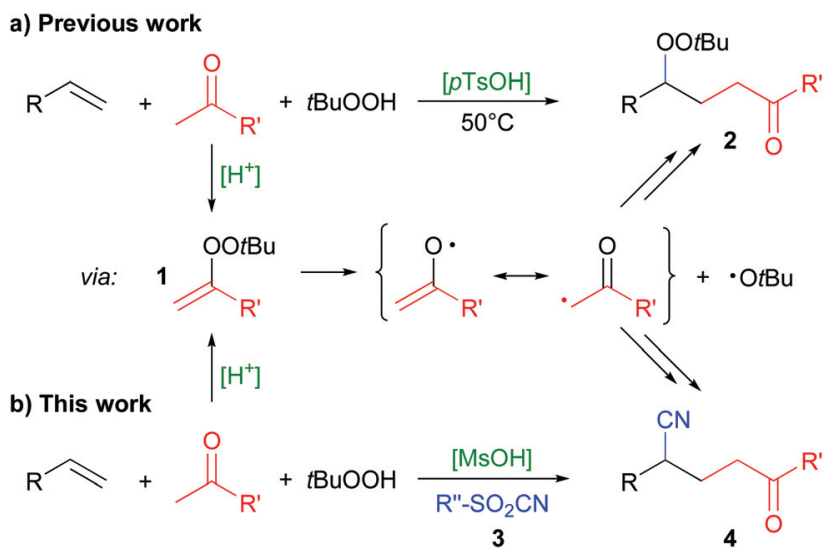

Scheme 1 Radical addition reactions via intermediate alkenyl peroxides (1) formed by acid catalysis. 
addition of ester, thioester or amide residues to olefins, requiring the use of stoichiometric organometallic reagents and prefunctionalized substrates, respectively. ${ }^{10 g-i}$ Radical trifluoromethylation with hypervalent iodine reagents together with cyanation has been reported by several groups. ${ }^{11}$ The groups of Liu and Zhu reported an intramolecular CN-transfer after radical addition, requiring special olefin substrates. ${ }^{12}$ The strategy of an intramolecular CN-transfer had previously been employed by the groups of Kalvoda, Watt and Nikishin to synthesize $\gamma$-cyanoketones. ${ }^{13}$ However, the yield in those reactions was typically rather low. Zhu et al. also described such products via a radical ring-opening reaction of cyclobutanols in the presence of $p$ TsCN. ${ }^{10 f}$

$\gamma$-Cyanoketones can also be prepared in a single step by conjugate addition reactions of ketones to vinyl nitriles and of nitriles to enones, respectively, generally requiring strong bases or complex catalysts. ${ }^{14}$ Applying chiral catalysts, this can allow the stereoselective synthesis of the products, but at the same time requiring nitriles with electron-withdrawing groups in the $\alpha$-position. ${ }^{15}$

The method we have developed could be complementary to those known cases. It uses readily available ketones and olefins and can be catalyzed by simple Brønsted acids. Directly adding ketone and cyanide radicals to an olefin could also allow the synthesis of $\gamma$-cyanoketones not easily accessible by the aforementioned methods.

\section{Results and discussion}

During the optimization of the method, we screened many different conditions, e.g. solvents, acids, cyanide reagents and concentrations. Full details can be found in the ESI, $\uparrow$ and exemplary results are shown in Table 1 . The desired product 4aa was formed in good yields from $p$ TsCN (3a), styrene (5a) and acetone (6a) in polar aprotic solvents (entries 1-3). Slightly better results were achieved when using ethyl- or methyl-

Table 1 Effect of reagents on the reaction outcome ${ }^{a}$

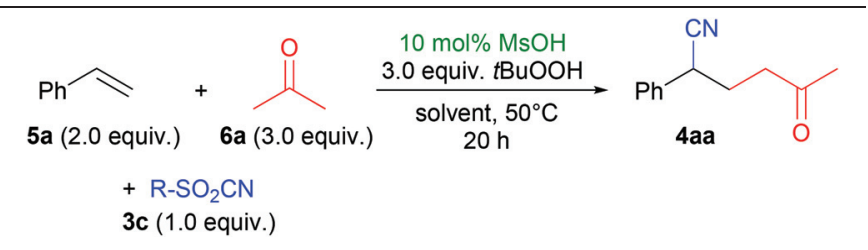

\begin{tabular}{llll}
\hline Entry & $\mathrm{R}(3)$ & Solvent & Yield $^{b} \%$ \\
\hline 1 & $p$ Tol (3a) & EtOAc & 60 \\
2 & $p$ Tol (3a) & $\mathrm{CHCl}_{3}$ & 48 \\
3 & $p$ Tol (3a) & $\mathrm{CH}_{2} \mathrm{Cl}_{2}$ & 61 \\
4 & $\mathrm{Et} \mathrm{(3b)}$ & $\mathrm{CH}_{2} \mathrm{Cl}_{2}$ & 64 \\
5 & $\mathrm{Me} \mathrm{(3c)}$ & $\mathrm{CH}_{2} \mathrm{Cl}_{2}$ & $69(63)^{c}$
\end{tabular}

${ }^{a}$ Screening reactions were typically performed with $0.5 \mathrm{mmol} 5 \mathrm{a}$, $1.25 \mathrm{mmol} 6 \mathrm{a}, 0.25 \mathrm{mmol} \mathrm{3}, 1.0 \mathrm{mmol} t \mathrm{BuOOH}$ and $0.025 \mathrm{mmol}$ acid in $0.2-1.0 \mathrm{ml}$ solvent under an argon atmosphere at $50{ }^{\circ} \mathrm{C}$. ${ }^{b}$ Determined by ${ }^{1} \mathrm{H}$-NMR. ${ }^{c}$ Isolated yield, reaction at a scale of $0.5 \mathrm{mmol} \mathrm{3,} 1.5 \mathrm{mmol} \mathrm{6a}, 1.5 \mathrm{mmol} t \mathrm{BuOOH}$ and $1.0 \mathrm{ml}$ of $\mathrm{CH}_{2} \mathrm{Cl}_{2}$.
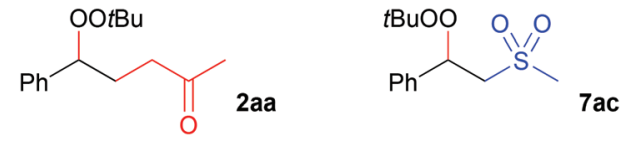

Fig. 1 Characterized byproducts of the reaction.

sulfonyl cyanides $\mathbf{3 b}$ and $\mathbf{3 c}$ (entries 4 and 5), $\S$ which can easily be synthesized by oxidation of the thiocyanates. ${ }^{10 h} \mathrm{We}$ achieved the best results with $3 \mathrm{c}$ in dichloromethane (entry 5).

In those reactions, two byproducts could be characterized (Fig. 1). Peroxyketone 2aa - the product formed in the absence of sulfonyl cyanides ${ }^{2 a}$ - was found in low amounts of up to $10 \%$ only. Peroxy-sulfone ${ }^{16}$ 7ac was formed in comparable, but generally lower yields than cyanoketone 4aa. In order to achieve good yields of the desired products, the olefin therefore has to be used in excess. Generally, sulfones 7 can easily be separated from nitriles 4 by column chromatography.

Using the conditions as of Table 1 , entry 5 , we investigated this method in the reactions of different ketones with styrene (Scheme 2). Simple open-chain and cyclic alkyl ketones gave the expected products 4aa-4ag. With methyl isopropyl ketone, the new bond was exclusively formed at the methyl group (4ab). Methyl aryl ketones afforded products $\mathbf{4 a h}-\mathbf{4 a l}$ in similar yields. The successful utilization of phenolic ketone $6 \mathbf{1}$ in the synthesis of $\mathbf{4 a l}$ is interesting, as many phenols are known as radical inhibitors. Two steroids, epiandrosterone $\mathbf{6 m}$ and pregnenolone 6n could be used as ketone component, giving the products 4am and 4an. The presence of a free hydroxyl group and an olefin in the ketone $\mathbf{6 n}$ did not hamper the yield significantly, as 4 an was formed in a relatively good yield of $43 \%$.

With pinacolone (6c) as a model ketone, we also tested the reaction with a variety of different aryl olefins (Scheme 3). A range of products $\mathbf{4 b c}-\mathbf{4 n c}$ with different aryl-substituents were formed in mostly good yields above $50 \%$, with the exception of the strongly electron-withdrawing and -donating substituents $\mathrm{CF}_{3}$, $\mathrm{CN}$ and $\mathrm{OMe}$ (4fc-4hc). A methyl substituent in the ortho-position also gave a good yield of $60 \%$ of 4 lc, but the ortho-bromide product 4nc gave a lower yield. Using indene (5q) as olefin gave the products $\mathbf{4 q c}$ and 4 qe (using cyclohexanone) in good yields, which are remarkable for their high trans-selectivity. For 4qc, a diastereomeric ratio of $>19: 1$ was determined in the crude reaction mixture, but after purification, we received the pure trans-product. In the case of $\mathbf{4 q e}$, two diastereomers were isolated which differ in the configuration at the $\alpha$-position of the cyclohexanone residue.

We also investigated the reaction between acetone or pinacolone and non-aryl olefins which on average gave lower yields than with styrene derivatives (Scheme 4). This is possibly due to the nature of the ketone-derived radicals, as this had also been observed during the synthesis of $\gamma$-peroxyketones. ${ }^{2 a}$ Noteworthy exceptions were the use of 1-octene (8b) and 6-cyano-1-hexene (8e), providing yields above $50 \%$. A natural product, limonene

$\S$ The superiority of MsCN (3c) over $p$ TsCN (3a) had already been noted before, see ref. $10 c$. 


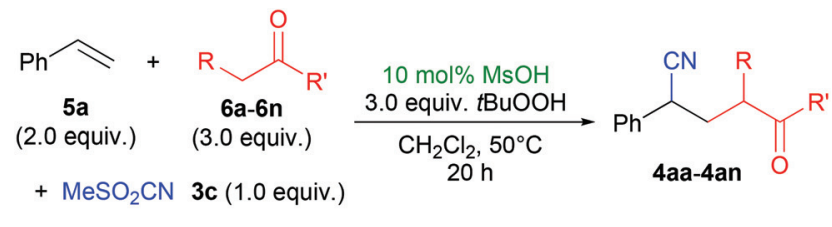<smiles>CC(=O)CCC(C#N)c1ccccc1</smiles><smiles>CC(C)C(=O)CCC(C#N)c1ccccc1</smiles><smiles>CC(C)(C)C(=O)CCC(C#N)c1ccccc1</smiles><smiles>CCC(=O)C(C)CC(C#N)C(C#N)c1ccccc1</smiles>

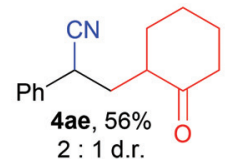<smiles>N#CC(CC1CCCC1=O)c1ccccc1</smiles>

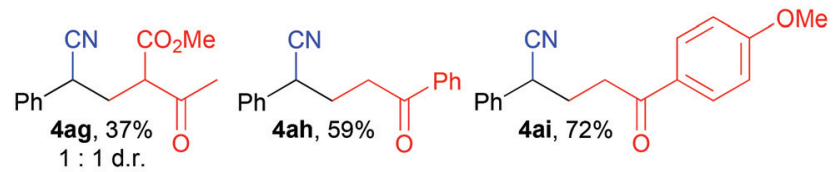<smiles>N#CC(CCC(=O)c1cccc(O)c1)C(=O)CCC(C#N)c1ccccc1</smiles>

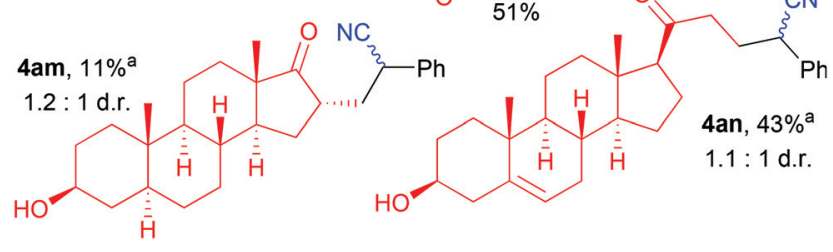

Scheme 2 Radical addition utilizing different ketones. ${ }^{a}$ Using 1.5 equivalents of ketone.

(8g) could be used as olefin component, albeit with only a rather low yield of $22 \%$ of product $9 \mathrm{gc}$. Interestingly, in the reactions with these olefins, the sulfonyl peroxide byproducts 7 were observed in traces only and could not be isolated.

Cyanoketones have previously been utilized as valuable synthetic intermediates that can be converted to lactones and piperidines, respectively, by reduction and subsequent cyclization. ${ }^{14 a, 15 c-e, 17}$ We have also applied these strategies to selected products, without purification after the first step (Scheme 5). A substituted $\delta$-valerolactone $\mathbf{1 0}$ was formed from product 4aa in a 1:1 mixture of diastereomers. Reduction of the nitrile group by hydrogenation in the presence of RANEY ${ }^{\circledR}$ Nickel and subsequent protection with a Boc-group gave piperidines 11 and 12 from cyanoketones 4 ai and 4qe, respectively.

Interestingly, the major diastereomer of $\mathbf{1 1}$ was found to obtain a solution conformation with both aryl groups in axial position, as shown in Scheme 5 (determined by NMR coupling constants and an NOESY experiment, see the ESI $\dagger$ for details). This at first surprising result was supported by DFT calculations: ${ }^{18}$ this conformation was indeed found to be more stable than the one with both aryl groups in equatorial position by $3.3 \mathrm{~kJ} \mathrm{~mol}^{-1}$ and also more stable than alternative boat
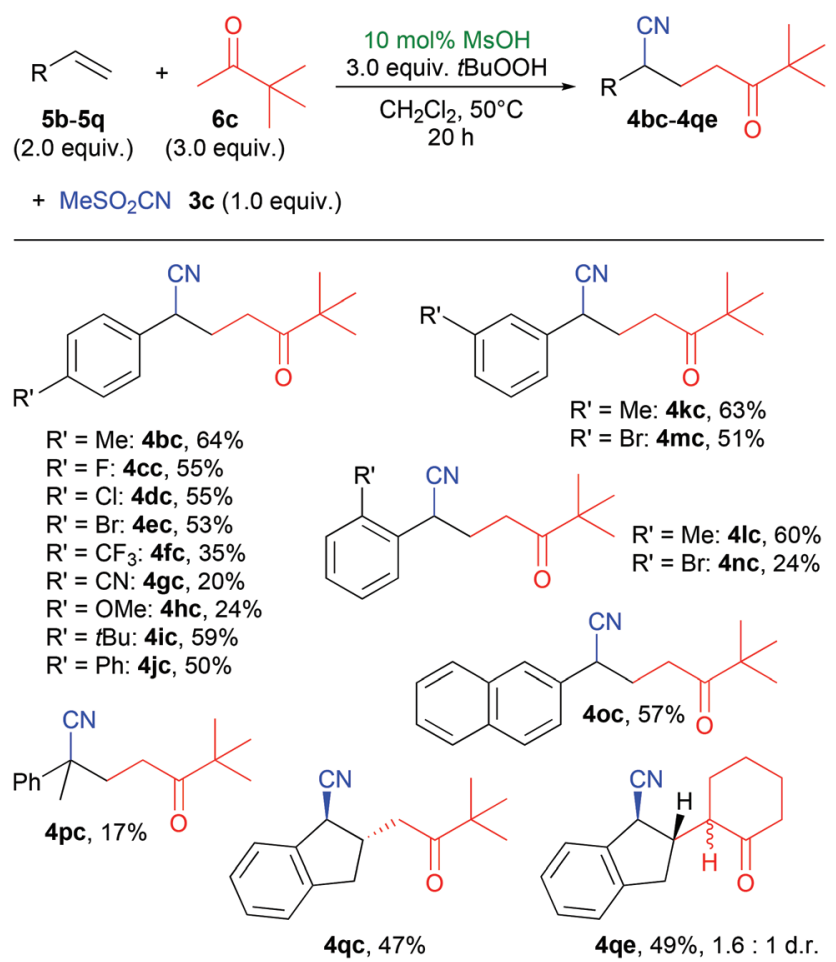

Scheme 3 Radical addition utilizing different aryl olefins.

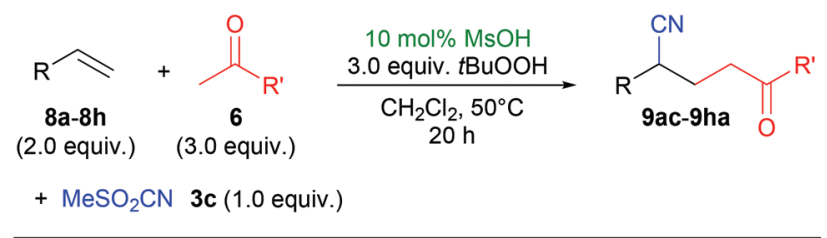<smiles>CCCCCCC(C#N)CCC(C)=O</smiles>

Scheme 4 Radical addition utilizing other olefins.

conformations. This results presumably from the avoidance of steric repulsion between the $p$-methoxyphenyl and the Boc group $^{19}$ and from a favorable orbital interaction between the nitrogen lone pair and the $\sigma^{*}$-bond of the $\mathrm{C}$-aryl bond (see the $\mathrm{ESI} \dagger$ for further details). 
<smiles>CC(=O)CCC([18OH])c1ccccc1</smiles>

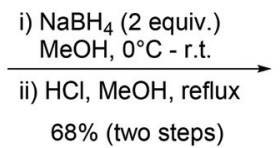<smiles>CC1CCC(c2ccccc2)C(=O)O1</smiles><smiles>COc1ccc(C(=O)CCC(C#N)c2ccccc2)cc1</smiles>
$3.2: 1$ d.r.

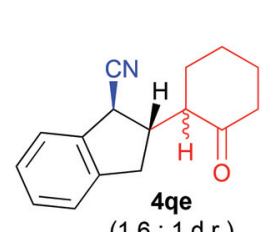

i) Raney-Nickel, $\mathrm{H}_{2}(650 \mathrm{psi})$ toluene/MeOH, $75^{\circ} \mathrm{C}$

ii) $\mathrm{Boc}_{2} \mathrm{O}$ (2.0 equiv.) $\mathrm{NEt}_{3}$ (2.0 equiv.) $\mathrm{CH}_{2} \mathrm{Cl}_{2}, 0^{\circ} \mathrm{C}$ - r.t. $77 \%$ (two steps)

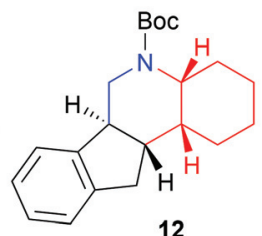

$12: 1: 1 \mathrm{~d} . \mathrm{r}$

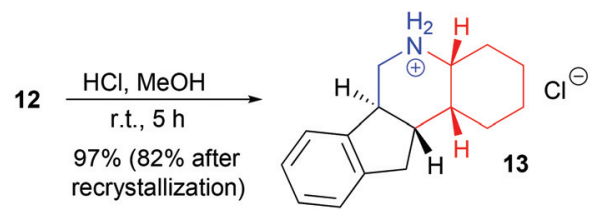

Scheme 5 Further transformations of selected products.

Tetracylic piperidine $\mathbf{1 2}$ was formed with a high preference for one diastereomer, as depicted in Scheme 5. The structure of the major one was confirmed by NMR spectroscopy and $\mathrm{X}$-ray crystallography of the corresponding ammonium salt 13, which was isolated diastereomerically pure after recrystallization (see the ESI $\dagger$ for further details).

In accordance with our earlier mechanistic studies of alkenyl peroxide formation $^{2 b}$ and based on the observation of byproducts 2 and 7, a radical mechanism appears reasonable (Scheme 6).
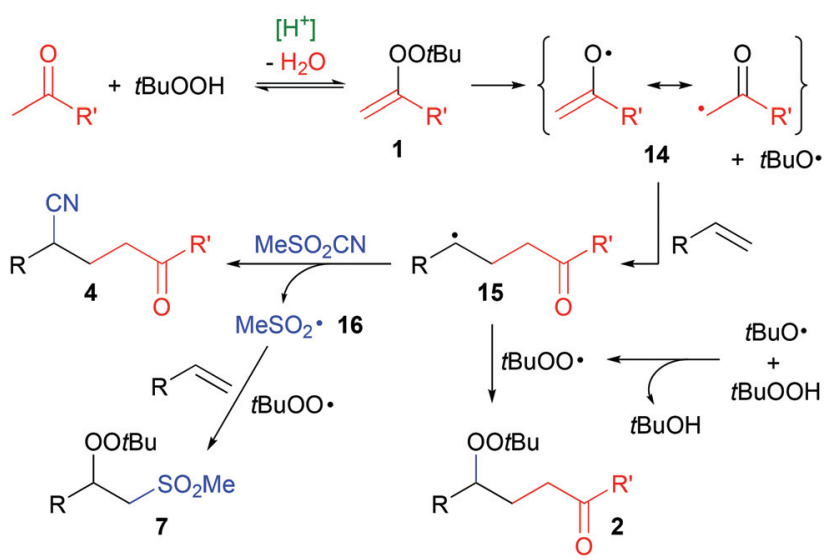

Scheme 6 Suggested reaction mechanism including formation of byproducts 2 and 7 .
Alkenyl peroxides $\mathbf{1}$ are formed by acid-catalyzed condensation of ketones and $t \mathrm{BuOOH}$. Rapid homolytic $\mathrm{O}-\mathrm{O}$ cleavage generates a tert-butyloxyl radical and resonance-stabilized radical 14, which adds to an olefin, forming the intermediate C-radical 15. Reaction with $\mathrm{MeSO}_{2} \mathrm{CN}^{10 c}$ generates the cyanoketones 4 and a sulfonyl radical 16. Rapid $\mathrm{H}$-atom transfer from $t \mathrm{BuOOH}$ to the oxyl radical generates the tert-butyl peroxyl radical, ${ }^{20}$ which can attack 15, forming peroxyketone 2 as minor byproduct. Major byproduct 7 is formed by subsequent attack of a sulfonyl and peroxyl radical on an alkene. ${ }^{16,21}$

\section{Conclusions}

In summary, we have developed a Brønsted-acid catalyzed synthetic method for the radical addition of ketones and cyanide to olefins, achieving the formation of two new $\mathrm{C}-\mathrm{C}$ bonds. A variety of ketones can be added to styrene derivatives but also to various alkyl olefins, giving a range of structurally diverse $\gamma$-cyanoketones. Selected products were further converted to a lactone and two piperidines, including the case of a tetracyclic piperidine that was thus synthesized in three steps only from simple starting materials.

\section{Conflicts of interest}

There are no conflicts to declare.

\section{Acknowledgements}

We thank the DFG (KL 2221/7-1 and KL 2221/4-2, Heisenberg scholarship to M.K.) and the Max-Planck-Institut fuer Kohlenforschung for funding. We are grateful to the Regional Computing Center of the University of Cologne for providing computing time of the DFG-funded High Performance Computing (HPC) System CHEOPS as well as for their support. Open Access funding provided by the Max Planck Society.

\section{Notes and references}

1 (a) X.-W. Lan, N.-X. Wang and Y. Xing, Eur. J. Org. Chem., 2017, 5821; (b) J. M. Muñoz-Molina, T. R. Belderrain and P. J. Pérez, Eur. J. Inorg. Chem., 2011, 2011, 3155; (c) H. Fischer and L. Radom, Angew. Chem., Int. Ed., 2001, 40, 1340; (d) B. Giese, Angew. Chem., Int. Ed. Engl., 1983, 22, 753.

2 (a) B. Schweitzer-Chaput, J. Demaerel, H. Engler and M. Klussmann, Angew. Chem., Int. Ed., 2014, 53, 8737; (b) B. Schweitzer-Chaput, T. Kurtén and M. Klussmann, Angew. Chem., Int. Ed., 2015, 54, 11848.

3 M. Klussmann, Chem. - Eur. J., 2018, 24, 4480.

4 (a) E. Boess, S. Karanestora, A.-E. Bosnidou, B. SchweitzerChaput, M. Hasenbeck and M. Klussmann, Synlett, 2015, 26, 1973; (b) X.-F. Xia, S.-L. Zhu, M. Zeng, Z. Gu, H. Wang 
and W. Li, Tetrahedron, 2015, 71, 6099; (c) S.-L. Zhu, P.-X. Zhou and X.-F. Xia, RSC Adv., 2016, 6, 63325; (d) C.-S. Wang, T. Roisnel, P. H. Dixneuf and J.-F. Soulé, Adv. Synth. Catal., 2019, 361, 445.

5 (a) M. S. Kharasch, J. Kuderna and W. Nudenberg, J. Org. Chem., 1953, 18, 1225; (b) G. I. Nikishin, G. V. Somov and A. D. Petrov, Russ. Chem. Bull., 1961, 10, 1924; (c) T. Iwahama, S. Sakaguchi and Y. Ishii, Chem. Commun., 2000, 36, 2317; (d) H. Wang, L.-N. Guo and X.-H. Duan, Chem. Commun., 2013, 49, 10370; (e) L. Zhu, H. Chen, Z. Wang and C. Li, Org. Chem. Front., 2014, 1, 1299; (f) X.-W. Lan, N.-X. Wang, W. Zhang, J.-L. Wen, C.-B. Bai, Y. Xing and Y.-H. Li, Org. Lett., 2015, 17, 4460; $(g)$ Y. Tian, C. Sun, R. X. Tan and Z.-Q. Liu, Green Chem., 2018, 20, 588.

6 (a) B. B. Snider, Chem. Rev., 1996, 96, 339; (b) B. B. Snider, Tetrahedron, 2009, 65, 10738; (c) M. Rössle, T. Werner, W. Frey and J. Christoffers, Eur. J. Org. Chem., 2005, 5031; (d) X. Zheng, S. Lu and Z. Li, Org. Lett., 2013, 15, 5432.

7 (a) C. Pan, Z. Yang, D. Gao and J.-T. Yu, Org. Biomol. Chem., 2018, 16, 6035; (b) X.-Q. Chu, H. Meng, Y. Zi, X.-P. Xu and S.-J. Ji, Chem. - Eur. J., 2014, 20, 17198.

8 (a) F. Zhang, P. Du, J. Chen, H. Wang, Q. Luo and X. Wan, Org. Lett., 2014, 16, 1932; (b) S. N. Gockel, T. L. Buchanan and K. L. Hull, J. Am. Chem. Soc., 2018, 140, 58.

9 (a) E.-A. I. Heiba and R. M. Dessau, J. Am. Chem. Soc., 1971, 93, 524; (b) U. Linker, B. Kersten and T. Linker, Tetrahedron, 1995, 51, 9917; (c) J. Xie and Z.-Z. Huang, Chem. Commun., 2010, 46, 1947; (d) Y. Li, J.-Q. Shang, X.-X. Wang, W.-J. Xia, T. Yang, Y. Xin and Y.-M. Li, Org. Lett., 2019, 21, 2227.

10 (a) R. G. Pews and T. E. Evans, J. Chem. Soc. D, 1971, 1397; (b) J.-M. Fang and M.-Y. Chen, Tetrahedron Lett., 1987, 28, 2853; (c) D. H. R. Barton, J. C. Jaszberenyi and E. A. Theodorakis, Tetrahedron, 1992, 48, 2613; (d) A.-P. Schaffner, V. Darmency and P. Renaud, Angew. Chem., Int. Ed., 2006, 45, 5847; (e) S. Kamijo, T. Hoshikawa and M. Inoue, Org. Lett., 2011, 13, 5928; $(f)$ R. Ren, Z. Wu, Y. Xu and C. Zhu, Angew. Chem., Int. Ed., 2016, 55, 2866; (g) N. S. Dange, F. Robert and Y. Landais, Org. Lett., 2016, 18, 6156; (h) H. Hassan, V. Pirenne, M. Wissing, C. Khiar, A. Hussain, F. Robert and Y. Landais, Chem. - Eur. J., 2017, 23, 4651; (i) R. Hara, C. Khiar, N. S. Dange, P. Bouillac, F. Robert and Y. Landais, Eur. J. Org. Chem., 2018, 4058.

11 (a) N. O. Ilchenko, P. G. Janson and K. J. Szabó, J. Org. Chem., 2013, 78, 11087; (b) Z. Liang, F. Wang, P. Chen and G. Liu, J. Fluorine Chem., 2014, 167, 55; (c) Y.-T. He, L.-H. Li, Y.-F. Yang, Z.-Z. Zhou, H.-L. Hua, X.-Y. Liu and Y.-M. Liang, Org. Lett., 2014, 16, 270; (d) A. Carboni, G. Dagousset, E. Magnier and G. Masson, Org. Lett., 2014, 16, 1240.

12 (a) N. Wang, L. Li, Z.-L. Li, N.-Y. Yang, Z. Guo, H.-X. Zhang and X.-Y. Liu, Org. Lett., 2016, 18, 6026; (b) R. Ren, Z. Wu,
L. Huan and C. Zhu, Adv. Synth. Catal., 2017, 359, 3052; (c) for a related strategy, see also: M. Wang, L. Huan and C. Zhu, Org. Lett., 2019, 21, 821.

13 (a) C. Meystre, K. Heusler, J. Kalvoda, P. Wieland, G. Anner and A. Wettstein, Experientia, 1961, 17, 475; (b) J. Kalvoda, Helv. Chim. Acta, 1968, 51, 267; (c) R. W. Freerksen, W. E. Pabst, M. L. Raggio, S. A. Sherman, R. R. Wroble and D. S. Watt, J. Am. Chem. Soc., 1977, 99, 1536; (d) Y. N. Ogibin, D. S. Velibekova, É. I. Troyanskii and G. I. Nikishin, Russ. Chem. Bull., 1981, 30, 475; (e) É. I. Troyanskii, V. V. Mizintsev, A. N. Molokanov, Y. N. Ogibin and G. I. Nikishin, Russ. Chem. Bull., 1986, 35, 671; $(f)$ É. I. Troyanskii, V. V. Mizintsev, A. N. Molokanov, Y. N. Ogibin and G. I. Nikishin, Russ. Chem. Bull., 1986, 35, 2499.

14 (a) H. Henecka, Chem. Ber., 1949, 82, 104; (b) R. Longeray and J. Dreux, Bull. Soc. Chim. Fr., 1963, 2805; (c) S. Paganelli, A. Sehionato and C. Botteghi, Tetrahedron Lett., 1991, 32, 2807; (d) M. Vogt, A. Nerush, M. A. Iron, G. Leitus, Y. Diskin-Posner, L. J. W. Shimon, Y. Ben-David and D. Milstein, J. Am. Chem. Soc., 2013, 135, 17004; (e) A. Nerush, M. Vogt, U. Gellrich, G. Leitus, Y. Ben-David and D. Milstein, J. Am. Chem. Soc., 2016, 138, 6985.

15 For reviews, see: (a) M. D. Díaz-de-Villegas, J. A. Gálvez, R. Badorrey and P. López-Ram-de-Víu, Adv. Synth. Catal., 2014, 356, 3261; (b) S. Jautze and R. Peters, Synthesis, 2010, 365. For selected examples, see: (c) M. S. Taylor, D. N. Zalatan, A. M. Lerchner and E. N. Jacobsen, J. Am. Chem. Soc., 2005, 127, 1313; (d) T.-Y. Liu, R. Li, Q. Chai, J. Long, B.-J. Li, Y. Wu, L.-S. Ding and Y.-C. Chen, Chem. Eur. J., 2007, 13, 319; (e) Y. Kawato, N. Takahashi, N. Kumagai and M. Shibasaki, Org. Lett., 2010, 12, 1484.

16 For an alternative synthesis of peroxy sulfones, see: R. Xu and Z. Li, Tetrahedron Lett., 2018, 59, 3942.

17 R. Longeray and J. Dreux, Compt. Rend., 1961, 252, 754.

18 Calculated at the DLPNO-CCSD(T)/def2-TZVPP/CPCM $\left(\mathrm{CHCl}_{3}\right) / /$ TPSS-D3/6-311+G(d,p)/CPCM level of theory.

19 For a review about conformational effects of this kind $(1,3$ axial strain), see: (a) F. Johnson, Chem. Rev., 1968, 68, 375. For selected related cases, see: (b) F. Johnson, Chem. Rev., 1968, 68, 375; (c) J. Quick, C. Mondello, M. Humora and T. Brennan, J. Org. Chem., 1978, 43, 2705.

20 (a) H. Paul, R. D. Small and J. C. Scaiano, J. Am. Chem. Soc., 1978, 100, 4520; (b) D. V. Avila, K. U. Ingold, J. Lusztyk, W. H. Green and D. R. Procopio, J. Am. Chem. Soc., 1995, 117, 2929.

21 For a mechanistic study on the addition of sulfonyl radicals, see: C. Chatgilialoglu, O. Mozziconacci, M. Tamba, K. Bobrowski, G. Kciuk, M. P. Bertrand, S. Gastaldi and V. I. Timokhin, J. Phys. Chem. A, 2012, 116, 7623. 